\title{
Arqueologia indígena dos povos do rio Mapuera: entrevista com Jaime Xamen Wai Wai
}

\author{
Igor M. Mariano Rodrigues * \\ Thiago Kater * * \\ Jaime Xamen Wai Wai ***
}

\begin{abstract}
RODRIGUES, I.M.M.; KATER, T.; XAMEN WAI WAI, J. Arqueologia indígena dos povos do rio Mapuera: entrevista com Jaime Xamen Wai Wai. R. Museu Arq. Etn. 35: 114-121, 2020.
\end{abstract}

Resumo: Durante a VI Semana Internacional de Arqueologia - Discentes MAE-USP, realizou-se uma entrevista com o arqueólogo Jaime Xamen Wai Wai. Convidado para palestrar na Mesa sobre Arqueologias Indígenas, aproveitouse a ocasião para entrevistá-lo a respeito de sua trajetória na Arqueologia, das motivações que o levaram a cursar a universidade e quais suas opiniões a respeito das contribuições que o olhar de um arqueólogo indígena pode trazer à disciplina. Estimulante, as respostas de Xamen trazem os desafios pessoais e as reflexões a respeito das práticas, categorias e classificações arqueológicas.

Palavras-chave: Arqueologia indígena; Arqueólogo indígena; Categorias arqueológicas

\section{Introdução}

To dia 24/05/2019, durante a

VI Semana Internacional de

Arqueologia - Discentes MAE-USP, realizou-se uma entrevista com o arqueólogo Jaime Xamen Wai Wai, na Faculdade de Filosofia e Ciências Humanas da Universidade de São Paulo. Concedida aos alunos do PPGArq-MAE/USP, Igor Rodrigues e Thiago Kater, a entrevista foi realizada após Jaime Wai Wai proferir sua palestra intitulada "Arqueologia-indígena dos povos do rio Mapuera, Oriximiná-PA.

\footnotetext{
* Doutorando em Arqueologia, Universidade de São Paulo. <igor_rodrigues@usp.br>

** Doutorando em Arqueologia, Universidade de São Paulo. <kater@usp.br>

*** Mestrando em Arqueologia, Universidade Federal de Minas Gerais. <jaimewaiwai@hotmail.com>
}

Experiência de arqueologia Wai Wai" no âmbito da Mesa Redonda "Arqueologias Indígenas".

Jaime Xamen Wai Wai é o primeiro arqueólogo indígena formado pela Universidade Federal do Oeste do Pará (UFOPA).

Atualmente é mestrando em Antropologia, com concentração em Arqueologia, na Universidade Federal de Minas Gerais e pesquisa sobre conhecimentos de seu povo acerca do passado e as narrativas arqueológicas realizadas anteriormente por pesquisadores não indígenas. Além do estudo entre seu povo, Jaime Wai Wai tem experiência de pesquisa etnográfica entre outros povos indígenas amazônicos como os Tenharim e Katukina.

A entrevista foi estruturada a partir de perguntas gerais relacionadas com a VI Semana Internacional de Arqueologia e também perguntas específicas ao próprio Jaime Wai Wai. 
Destaca-se que, de acordo com as respostas de Jaime, outras perguntas foram elaboradas no momento para realçar alguns pontos apenas mencionados nas respostas.

Optou-se por apresentar a entrevista na forma de texto a partir da fala de Jaime, com base em conceitos e métodos da História Oral praticada pelo Núcleo de História Oral da Universidade de São Paulo (NEHO/USP) (Meihy \& Ribeiro 2011). Seguiu-se o gênero 'história oral temática', pela qual se busca destacar a experiência individual da pessoa entrevistada a respeito de um determinado assunto, valorizando pontos de vistas que corriqueiramente estão suprimidos (Meihy \& Ribeiro 2011). A elaboração das perguntas, transcrição e organização das respostas, assim como a síntese do texto foram feitas por Igor Rodrigues e Thiago Kater que também trabalharam na revisão final do texto juntamente com Jaime Wai Wai.

\section{Da aldeia para a universidade: fragmentos de uma trajetória}

Jaime Xamen Wai Wai nasceu e cresceu na aldeia Mapuera, situada na margem esquerda do rio homônimo, dentro da Terra Indígena Nhamundá-Mapuera, adjacente às Terras Indígenas Trombetas-Mapuera e KaxuyanaTunayana. Formando um contínuo, essas três terras indígenas estão situadas entre os estados do Pará, Amazonas e Roraima (FIGURAS 1 e 2).

Jaime estudou até a oitava série do ensino fundamental na própria aldeia Mapuera, pois na época lá ainda não havia ensino médio, como hoje em dia. Após concluir seus estudos, pensando que já teria terminado tudo, ele planejou viajar e vender artesanatos em cidades como Manaus e Belém, por exemplo. Contudo, seu irmão mais velho, que no momento cursava Teologia em Manaus, lhe informou que ainda existiam mais estudos a serem realizados. Assim, Jaime se mudou para a cidade de OriximináPA e concluiu o ensino médio em 2012. Após isso, teve notícias da abertura de três processos seletivos para indigenas, um em Santarém com enfoque multidisciplinar, graduação em medicina em Belém e curso de teologia em Manaus. Até então Jaime não sabia da existência da Arqueologia. Ao refletir sobre a distância destas cidades em relação a Oriximiná, município no qual a aldeia Mapuera está inserida, Jaime optou por concorrer no processo seletivo especial para alunos indígenas da UFOPA em Santarém, visto ser o mais próximo.

Segundo Jaime, ele foi aprovado no curso de História e ao logo de seu contato com amigos e explicações dadas por professores em sala de aula, especialmente o Prof. Dr. Claide Moraes, se interessou por Arqueologia, pois além das fontes materiais com as quais esse campo do saber costuma lidar estarem presentes na vida da comunidade, a Arqueologia também pode dialogar com a História. Portanto, as disciplinas do curso de Arqueologia, assim como suas fontes de pesquisa, atraíram Jaime, fazendo-o mudar seu percurso na graduação. Ao observar que dentro desta disciplina somente os brancos contavam a história dos indígenas a partir dos materiais arqueológicos, Jaime percebeu a necessidade dessa história começar a ser contada também pelos próprios indígenas dentro do meio acadêmico.

De início, essa tarefa não foi fácil e por vezes muito confusa, especialmente ao tentar conversar com os mais velhos que omitiam informações e explicações, fornecendo-as somente depois de muita insistência. A noção de Arqueologia como algo necessariamente relativo a um passado distante, morto e enterrado causou problemas na tradução de conceitos em conversas com os anciões nas aldeias. Por exemplo, se valendo de uma lâmina de machado e fragmentos cerâmicos que existem aos montes em sua aldeia, ao conversar com seu pai Poriciwi (com mais de 80 anos) no intuito de saber mais da história pessoal dele e de seu povo, Jaime ouviu: "Eu não sou antigo, estou presente e não estou morto. Você não está estudando só história antiga. A história não fica só na memória, ela segue e eu te passei algumas histórias que você agora sabe". Com isso, Jaime ficou impressionado e percebeu que a história e arqueologia estão presentes atualmente na comunidade, porém dificilmente isso é visto de forma clara nos 
Arqueologia indígena dos povos do rio Mapuera: entrevista com Jaime Xamen Wai Wai R. Museu Arq. Etn., 35: 114-121, 2020.

corpos, nas festas e nos rituais. Para saber e entender é necessário perguntar às pessoas mais antigas na comunidade, é preciso aguçar a memória delas e também articular visões de mundo bastante distintas. A arqueologia está presente na comunidade, mas não sob esse nome, talvez o nome mais apropriado seja memória para Jaime.

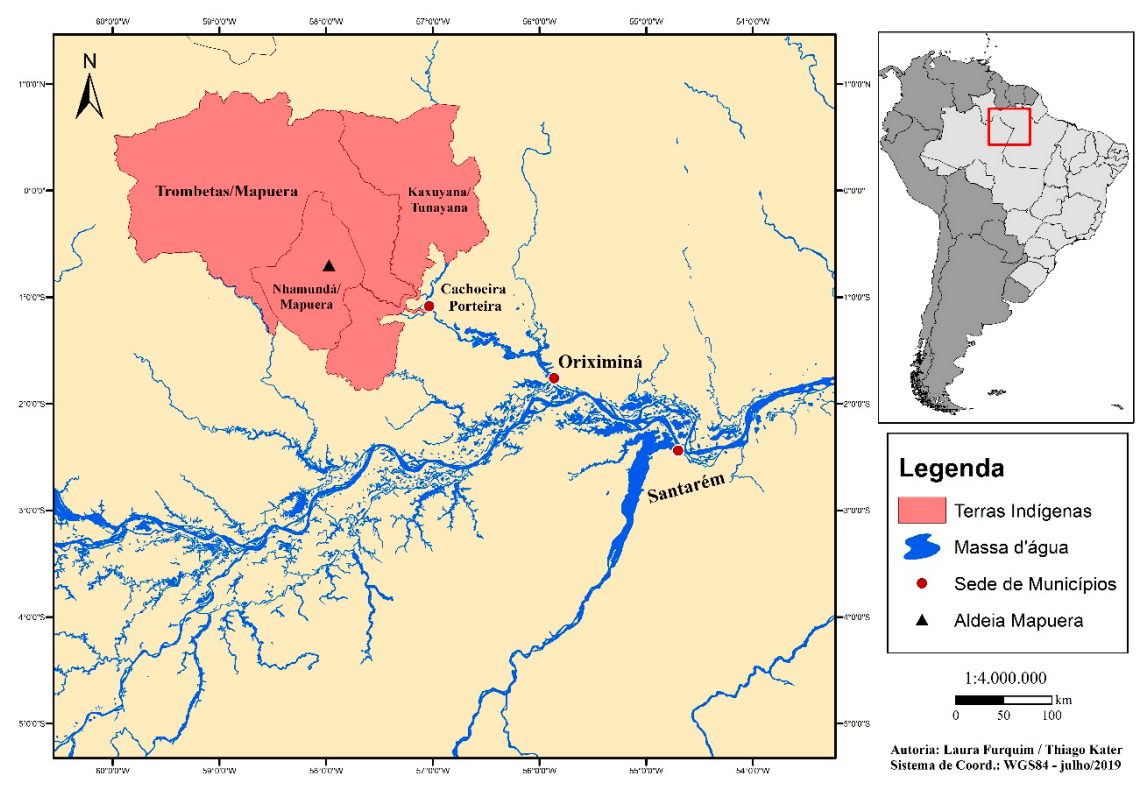

Fig. 1. Mapa com localização da aldeia Mapuera e Terras Indígenas mencionadas.

Fonte: Laura Furquim e Thiago Kater.

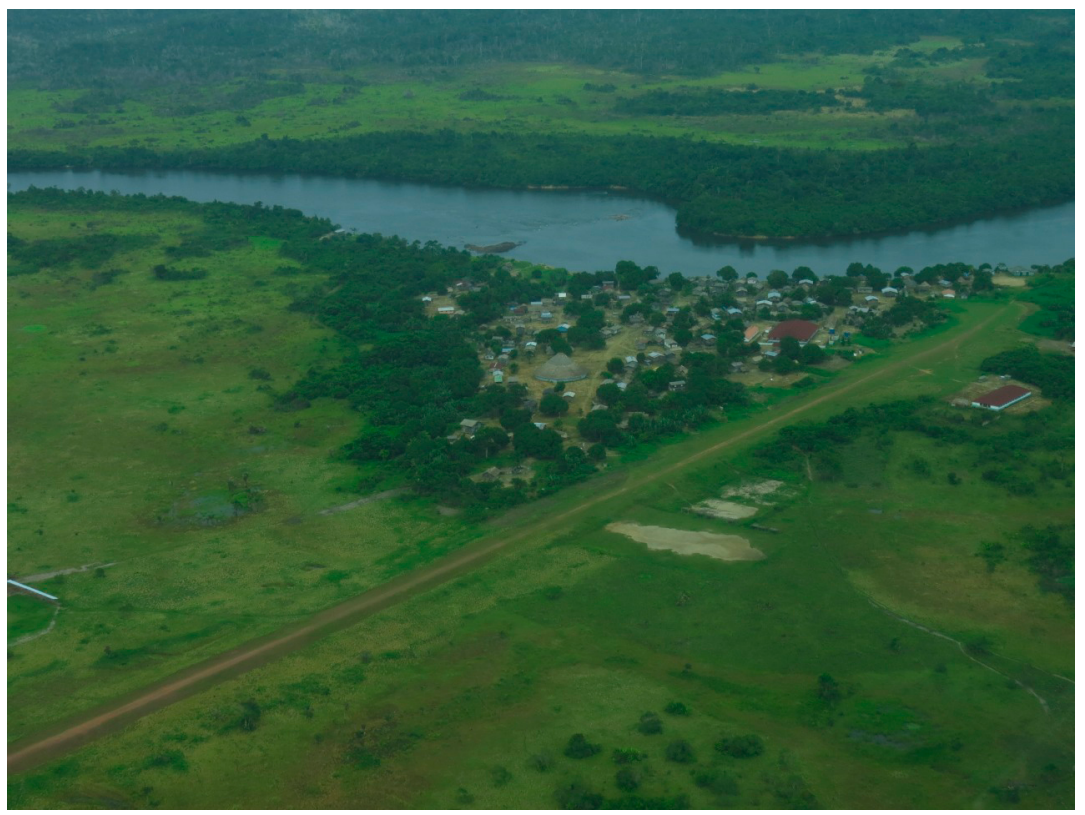

Fig. 2. Vista aérea da aldeia Mapuera.

Fonte: Foto de Igor Rodrigues, 2019. 
Um dos principais problemas enfrentados no início das conversas de arqueologia com os mais antigos é a forma como os brancos costumam discriminar e delimitar os chamados "vestígios arqueológicos". Para os Wai Wai, tais vestígios podem ser vistos não só nos próprios lugares em que habitam, eles estão em toda parte. Como afirmou Jaime: "arqueologia é tudo". Uma montanha, uma pedra ou rio podem ser concebidos como "vestígios arqueológicos", como "arqueologia". Eles têm histórias. Tudo o que pode conter marcas culturais dos ancestrais está incluído dentro da arqueologia. Por exemplo, a "pedra do guariba", localizada no meio do rio Mapuera em frente à aldeia homônima, remete à história de seres que ainda vivem dentro da água, conhecidos como okoimoyana ("povo da anaconda"). Eles são seres muito antigos e poderosos que podem aparecer na forma de humanos e também de animais. Em suma, não é só a cerâmica, as lâminas de machado de pedra e as terras pretas, por exemplo, que podem ser o que os brancos chamam de "vestígios arqueológicos", mas sim toda a paisagem, toda a região geográfica. Tudo está costurado, junto e misturado.

Após se graduar, Jaime ficou longe da universidade por dois anos, morando em Oriximiná e trabalhando na Associação dos Povos Indígenas do Mapuera. Chegou a prestar o concurso de mestrado na Universidade Federal do Amazonas, mas infelizmente não passou. Isso o deixou triste e desanimado, chegando a pensar em abandonar os estudos e voltar para a aldeia. Todavia, com o incentivo de amigos que já tinham estudado na Universidade Federal de Minas Gerais, assim como de seus pais e demais familiares, Jaime Wai Wai concorreu e foi aprovado no mestrado dessa instituição.

Atualmente seu projeto de pesquisa pretende contar a história de diversos lugares habitados pelos antigos Wai Wai. Quais eram as aldeias, quem morou nelas, quais eram os líderes, são algumas perguntas que ele quer responder. Para Jaime, sua pesquisa é muito importante, pois atualmente existem poucos anciões Wai Wai que sabem muita coisa, então, caso eles venham a falecer, muitas referências e histórias irão se perder. Sua pesquisa salvará a história e memória dos lugares, o que é importante para diversos povos do Mapuera. Enquanto arqueólogo indígena, ele reunirá informações para os que posteriormente quiserem saber e até escrever mais sobre essa história. Tudo deverá ficar registrado para que filhos e netos possam saber disso no futuro, ainda que possam existir várias histórias paralelas, uma vez que os povos do Mapuera atualmente são compostos por pessoas que se denominam Xerew, Katwena, Mawayana, Hixkaryana, Tunayana, entre muitos outros ${ }^{1}$. Por fim, os resultados de sua pesquisa poderão ser levados aos alunos da escola nas aldeias, como conteúdo de história dos indígenas a partir dos próprios indígenas, inclusive na língua Wai Wai, para além de uma história contada pelos brancos.

\section{Sobre a VI Semana Internacional de Arqueologia dos discentes do MAE/USP}

Jaime acredita ser importante a presença de indígenas, acadêmicos ou não, em eventos científicos. Aliás, para ele é fundamental que lideranças e pesquisadores indígenas sejam convidados a participar de encontros e debates sobre a construção do conhecimento científico, especialmente quando estão envolvidas questões pertinentes aos povos indígenas. Os indígenas devem ser convidados não só para estar no evento, mas para discutir os modos de fazer ciência, terem voz e serem ouvidos de fato.

Sua participação na Mesa Redonda "Arqueologias Indígenas", juntamente com as pesquisadoras Dra. Patrícia Ayala Rocabado e Dra. Camila Jácome, foi muito proveitosa e significativa. Jaime achou importante ter ouvido histórias de outros povos e culturas indígenas. Foi um espaço para ele poder apresentar a história e cultura de seu povo, além de contar informações que ainda não foram ditas aos pesquisadores não indígenas.

1 Para mais informações sobre os Wai Wai, ou Waiwai, consultar os trabalhos de Howard (2001), Caixeta de Queiroz (2008, 2015), Jácome (2017) e Xamen Wai Wai (2017). 
Em relação aos museus, tema levantado na apresentação da arqueóloga Dra. Patrícia Ayala Rocabado, e ao fato de que alguns possuem coisas/objetos do povo Wai Wai, especialmente objetos etnográficos como peneiras, pentes, tangas, entre outros, Jaime se sente incomodado e disse que isso não é sentido só por ele, mas também compartilhado por seus parentes. Ele constantemente se pergunta "por que os brancos guardam nossas coisas? Por que a gente não guarda as coisas deles? O lugar do material arqueológico e das coisas de nossa cultura é aqui na nossa terra e não é lá [no museu]". Ao lembrar do incêndio ocorrido no Museu Nacional, que entristeceu e mexeu muito com os sentimentos de diversos povos indígenas, Jaime pensa que se os brancos não conseguem cuidar bem eles têm que devolver. Uma vez, em conversa sobre museu com um colega do povo Munduruku, que também é estudante indígena de arqueologia, Jaime ouviu:

Museu só na cidade está errado, é preciso ter museu nas comunidades. Os brancos têm que ir conhecer nossa região, os museus precisam estar nas aldeias e não só nas cidades. Por que eles levam os esqueletos humanos para esses museus? Isso está errado, pois a gente não leva os esqueletos dos parentes deles. Será que eles iam gostar se a gente fizesse isso?

Concordando com o pensamento desse colega, Jaime acredita ser necessário construir um espaço museológico na aldeia para trazer de volta as coisas Wai Wai, mesmo que isso seja um processo lento. A ideia de ter um museu nas aldeias ainda precisa ser pensada com calma.

\section{A relação entre diferentes povos indígenas na universidade}

$\mathrm{Na}$ UFOPA, Universidade em que fez sua graduação, Jaime teve a oportunidade de conhecer estudantes indígenas de diversos povos e lugares. Estima que deve ter conhecido estudantes de quase 20 povos diferentes.
A diferença linguística entre eles contribuiu muito para o isolamento entre os estudantes que acabaram convivendo mais com seus pares. Tais diferenças ocasionaram, pontualmente, até alguns desentendimentos e discussões, já que a não compreensão de outras línguas e costumes levava à má interpretação de algumas situações, sendo constante as suspeitas de deboche e menosprezo. Os estudantes evitaram estudar juntos e cada povo buscou um espaço próprio, como a sala dos estudantes Wai Wai, dos estudantes Munduruku, dos estudantes indígenas do baixo Tapajós e assim por diante. Todavia, apesar dessa separação e da vivência de organizações específicas conforme cada povo, Jaime destacou que aos poucos os estudantes indígenas começaram a se juntar, somando suas forças para poder lutar por algo em comum.

Lembrou ainda que os brancos, professores ou não, sempre quiseram que os estudantes indígenas de diversos povos se juntassem e se adaptassem, mas para alguns isso foi um grande incômodo. Por isso o isolamento. De acordo com suas palavras:

No mundo Brasil, a gente quer juntar, ter força para poder lutar, pela nossa resistência, mesmo que [os povos de] cada estado, defenda seus lugares. Se eu for para outro lugar, em Belém, por exemplo, terá outros parentes que não querem que eu trabalhe lá, pois essa é a região deles, mas isso não impede de lutar junto. Independente das diferenças, pequenas organizações em diferentes niveis, tem uma luta comum, é um outro tipo de organização, como a Terra Livre ${ }^{2}$ que ocorreu em Brasilia em benefício de todos os povos indígenas.

2 Referência ao movimento "Acampamento Terra Livre” que, em linhas gerais, é um movimento indigena pacífico, que ocorre há mais de 15 anos, reunindo diversos povos indígenas cujas principais lideranças vão aos Ministérios, Supremo Tribunal Federal e Parlamentos para, por exemplo, entregar documentos, fazer reivindicações e lutar por questões que afetam diretamente a vida dos povos originários. 
O que os não indígenas podem aprender com os indígenas sobre passado indígena: palavras finais

A participação em congressos, apresentação de trabalhos e leitura de textos acadêmicos escritos por brancos fez Jaime refletir e constatar que grande parte da falta de aprofundamento e entendimento do pensamento indígena por parte dos brancos, que se esforçaram tanto para coletar, reunir e entender diferentes histórias e culturas, é "culpa dos velhos que não contaram para os pesquisadores toda a história, a cultura e a origem. Tem muita parte que eles não contaram". Não obstante, ele reconhece que algumas partes foram contadas sim, mas não foram realmente compreendidas pelos brancos.

Em todo caso, há fatos e entendimentos que não estão presentes nos trabalhos produzidos pelos brancos, por estes, no entender de Jaime, não aceitarem determinadas explicações e interpretações indígenas que geralmente são vistas como puramente fictícias, entendidas somente enquanto "mito". Para Jaime, as interpretações indígenas não são inventadas e não são fantasiosas, elas são histórias de verdade: "Os brancos têm que aceitar quando a gente conta algumas coisas, a história dos nossos povos, os detalhes”. Ademais, ele adicionou que as interpretações dos próprios indígenas "precisam ser levadas a sério, corrigindo as dos brancos, que precisam lidar com isso, aprender devagar a entender". Uma das missões dos acadêmicos indígenas é corrigir algumas interpretações dos brancos.

Como exemplo final, Jaime mencionou rapidamente o caso da cerâmica denominada Konduri da região do baixo Trombetas. Para ele, "a interpretação dos brancos está tudo ok, mas nosso lado da interpretação tem que ser levado a sério", como a indicação, em sua palestra, de que as figurações de animais em cerâmica testemunham que os xamãs de antigamente conversavam com os espíritos dos animais. Ainda, há o que ele defendeu em sua monografia de conclusão de curso (Xamen Wai Wai 2017).

Apesar de breve, a entrevista com Jaime Xamen Wai Wai tocou em pontos importantes, chamando a atenção para algumas concepções e práticas que os não-indígenas têm e fazem com os materiais de diversos povos indígenas, muitas vezes sem considerar seriamente seus posicionamentos. A última resposta desse arqueólogo indígena Wai Wai encerrou a conversa com uma frase ao mesmo tempo convidativa e provocativa: "As informações que os indigenas passam precisam ser dialogadas nas pesquisas, pois isso é a construção de uma ciência".

"Ero wa makî, kirwanhe. Amne hara."

("É só isso, está bem. Até mais.")

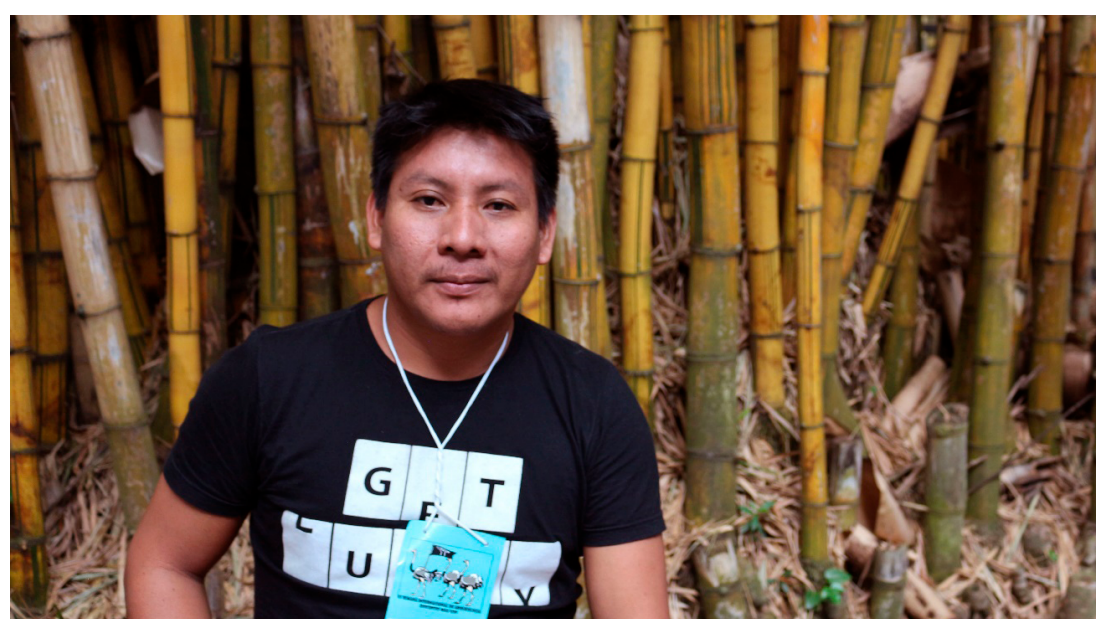

Fig. 3. Jaime Xamen Wai Wai após entrevista na entrada do Departamento de História da Faculdade de Filosofia, Letras e Ciências Humanas da Universidade de São Paulo.

Fonte: Foto de Thiago Kater, 2019. 


\section{Nota de pesar}

A entrevista acima foi realizada em 2019, como posto. Infelizmente, em pouco mais de um ano depois, a pandemia de Covid-19, que ainda se faz presente em nossas vidas, levou duas pessoas extremamente importantes para a vida de Jaime Xamen Wai Wai: seu pai Renato Poriciwi Wai Wai faleceu no dia 5 de junho de 2020 e tinha em torno de 80 anos; seu irmão mais velho, Fernando Makari Wai Wai, 59 anos, faleceu cerca de um mês depois de Poriciwi. Essas duas pessoas foram fundamentais não só para a educação de Jaime enquanto pessoa, mas também em sua trajetória acadêmica. Deste modo, optou-se por acrescentar ao texto os seguintes dizeres emocionados de Jaime, ditos pelo aplicativo WhatsApp:

Meu pai sempre foi uma grande biblioteca das nossas histórias, dos Wai Wai que moravam no rio Kikwo [Baracuxi, tributário do Alto Mapuera]. Através de sua memória ele sempre contava, assim né, a nossa trajetória como Wai Wai. Ele faleceu de Covid-19. Meu pai é ao mesmo tempo meu amigo e meu professor. Então, meu irmão aprendeu bastante coisa com meu pai. Ele sabia muita coisa, tinha conhecimento sobre paisagem, sobre rios, lagos e espíritos. Meu irmão. Ele sabia muita coisa. Ele era pastor e aprendeu com meu pai e minha família, através de tudo que viu durante a infância e adolescência. Ele também adoeceu depois, por causa de Covid-19 e chegon a falecer. Nossa família perdeu pai e filho. Hoje é momento de escrever essas histórias. Nós Wai Wai temos que contar para os outros. Temos que dividir, com os outros, esse conhecimento. Então, a gente está, assim, reavivando, escrevendo o que está na memória. Escreve isso, complementa. Eu sou o caçula. Estou escrevendo essa história. Vou tentar replantar essa história, vou contar e escrever. Como porta-voz. Então, vou fazer isso por meu povo e minha família...

A perda de Jaime não foi um caso isolado. Mais de cento e sessenta povos diferentes perderam seus entes queridos e muitos sábios anciões. Diante do descaso do Governo Federal, iniciativas buscaram registrar esse momento doloroso e recordar quem se foi. Os povos indígenas permanecem em sua luta contra os recorrentes apagamentos de suas histórias e de suas vidas no Brasil. Para maiores informações sobre a pandemia e os povos indígenas recomendamos os seguintes sites:

https://covid19.socioambiental.org/

https://memorialvagalumes.com.br/

RODRIGUES, I.M.M.; KATER, T.; XAMEN WAI WAI, J. Indigenous Archeology of the Mapuera River peoples: interview with Jaime Xamen Wai Wai. R. Museu Arq. Etn. 35: 114-121, 2020.

Abstract: During the VI International Week of Archeology of Students MAEUSP, an interview with archaeologist Jaime Xamen Wai Wai was held. Invited to speak about Indigenous Archaeologies, the occasion was also used to conduct an interview with him about his trajectory in Archeology, the motivations that led him to go the university and what his opinions about the contributions that an indigenous archaeologist perspective can bring to the archaeological field. Excitingly, Xamen's answers bring the personal challenges and reflections on archaeological practices, categories and classifications.

Keywords: Indigenous archeology; Indigenous archaeologist; Archaeological categories 


\section{Referências bibliográficas}

Caixeta de Queiroz, R. 2008. Trombetas-Mapuera: território indígena. Funai-PPTAL, Brasília.

Caixeta de Queiroz, R. 2015. Cosmologia e história Waiwai e Katxuyana: sobre os movimentos de fusão e dispersão dos povos (Yana). In: Grupioni, D.F.; Andrade, L.M.M. (Orgs.). Entre águas bravas e mansas: índios \& quilombolas em Oriximiná. Comissão Pró-Índio de São Paulo/ Iepé, São Paulo, 104-132.

Howard, C.V. 2001. Wrought identities: the Waiwai expeditions in search of the "unseen tribes" of Northern Amazonia. Tese de doutorado. University of Chicago, Chicago.
Jácome, C.P. 2017. Dos Waiwai aos Pooco: fragmentos de história e arqueologia das gentes dos rios Mapuera (Mawtohrî), Cachorro (Katxuru) e Trombetas (Kahu). Tese de doutorado. Universidade de São Paulo, São Paulo.

Meihy, J.C.S.B.; Ribeiro, S.L.S. 2011. Guia prático de história oral: para empresas, universidades, comunidades, famílias. Contexto, São Paulo.

Xamen Wai Wai, J. 2017. Levantamento etnoarqueológico sobre a cerâmica Konduri e ocupação dos Wai Wai na região da Terra Indígena Trombetas-Mapuera (Pará, Brasil). Trabalho de conclusão de curso. Universidade Federal do Oeste do Pará, Santarém. 